\title{
Special Issue: Reading for pleasure: supporting reader engagement
}

Contents

\section{Editorial}

Teresa Cremin and Gemma Moss

Affective encounters: Enchantment and the possibility of reading for pleasure Cathy Burnett and Guy Merchant

Reading and company: Embodiment and social space in silent reading practices Anezka Kuzmicova

The pleasures of reading non-fiction Joy Alexander and Ruth Jarman

Pedagogy for reading for pleasure in low socio-economic primary schools: Beyond 'pedagogy of poverty'?

Amelia Hempel Jorgensen, Teresa Cremin, Diane Harris and Liz Chamberlain

"Not Applicable": Whose job is it to build lifelong readers in the classroom

Rhoda Myra Garces-Bacsal, Ruanni Tupas, Sarinajit Kaur, Agnes Paculdar and Emmanuel Baja

Readers in the round: A holistic approach to children's engagements with texts

Rebecca Parry and Lucy Taylor

One Child Reading: My Auto-Bibliography Margaret Mackey

Reviewed by Christine Hall

Reading by Right: Joy Alexander

Reviewed by Mathew Tobin

Editorial

Reading for Pleasure: Supporting reader engagement

Teresa Cremin and Gemma Moss

Education systems worldwide face the challenge of balancing a desire to raise young readers' attainment, whilst simultaneously seeking to create vibrant reading communities of readers within and beyond school. Many countries, cognisant of the bi-directional relationship between reading attainment and positive attitudes to reading (OECD, 2002, 2010), are now paying increased attention to the concepts of reader engagement and reading for pleasure in both policy and practice. This Special Issue of Literacy brings into the spotlight recent empirical work and scholarly discussions which foreground young people's volitional reading and in so doing explores new 
questions, connections and possibilities for future research. The articles included examine the lived reading practices of children and young adults, as well as teachers and student teachers, in a range of contexts. In contrast to the traditionally conceived view of reading as an individual, rather than a social act or process, they all recognise the highly social nature of reading and the importance of the cultural and material context for reading in shaping how it gets done.

In the opening paper, Cathy Burnett and Guy Merchant face head-on the historical alignment of pleasurable reading with literary fiction and draw our attention to the variety of literacy practices in which humans engage, and the pleasures that are often generated as we respond to, through and around digital media. Their paper invites us to re-view reading for pleasure in this digital age. Through illuminating vignettes of young people and adults, (as well as themselves), engaged in everyday practices they highlight the sense of affective engagement and the 'mood of enchantment' which pervades. Linking this to Bennet's (2001) work on enchantment they argue for 'seeing reading for pleasure as an affect generated in the relations between readers, texts and things'. Linking also to literary studies that draw on new materialism, their examples reveal the spontaneity involved when digital texts are in play and the atmosphere generated and shared through material-social relations. This notion of the 'mood of enchantment' is both intriguing and beguiling. As they explain, engagement with digital texts has the potential to generate new interactions and connections with the immediate present and with what has happened or is happening elsewhere. In their explorations of material-social relationality and potentiality they remind us of the need for an inclusive take on reading for pleasure and the value of attending to the embedded nature of reading. Their work extends beyond studies which have foregrounded reading as relational (e.g. Moss and McDonald, 2004; Cremin et al., 2014) and highlights reading as embedded in complex networks of people and things and in the ephemeral, everyday and sometimes trivial encounters that life comprises.

Our next paper, cognisant of the embodied and physically situated nature of reading also challenges us to take a wider view. In 'Reading and company: embodiment and social space in silent reading practices', Anezka Kuzmicova reports the findings of an empirical study which explored the role of the environment in influencing the reader's purpose, text type chosen and device selected (e.g. print book, laptop, e-reader, smartphone). This paper focuses on the sociality of individual silent reading and the readers' evident awareness of the presence and activity of others when they were reading. Focus groups with keen readers (university students) from six European countries were combined with follow up questionnaires. The findings regarding reading in the home reveal considerable diversity in terms of favorite places and positions; with comfort and relaxation being key for many when engaged in leisure reading. What was striking was the value afforded by company whilst reading silently and the 'affective impact of the unobtrusive physical presence of others' regardless if the reading was for leisure or study purposes. When reading in dedicated reading spaces (such as university libraries), again the presence, perceived status and various activities of other people in the space were recognized as influential, as they were in non-dedicated reading spaces of a more public nature. In the latter contexts more use of smart phones, more variety in physical actions and social interaction around what was being read was reported. In a manner resonant of Burnett and Merchant's attention to the embedded nature of reading in material-social relations, Kuzmicova's paper underscores the importance of understanding the nuanced embodied-social complexities of reading environments: at home, in schools, libraries and elsewhere. Reading in the proximity of others unquestionably deserves more attention.

Our third paper also encompasses awareness of the social nature of the reading experience but in the context of schooling and with reference to 8-14 year olds reading science-information books in Ireland. In 'the pleasures of reading non-fiction' Joy Alexander and Ruth Jarman assert, theorize and 
demonstrate the potency of non-fiction texts as a resource for pleasurable engagement. They draw on 'Project 500' (named after the Dewey classification system) and detail the extensive data gathered across three years from teachers (primary and post-primary) students and librarians. The reading challenge involved included passports and stickers which were valued by the young people, but Alexander and Jarman makes clear that it was pleasure in reading not the extrinsic factors that the team were seeking and the evidence attests to considerable success in this regard. Initially uninterested and worryingly negative about potentially reading science books, the young people clearly became hooked over the project. The key influencing factors appeared to be the very high quality of the books selected, the optional activities linked to them and the opportunities that were afforded to talk about these engaging texts and to share them with friends and family. The paper closes with a discussion differentiating fiction and non-fiction albeit whilst recognizing similarities and, drawing on Rosenblatt's (1995) efferent and aesthetic stances, offers a useful typology of the pleasures of non-fiction.

Our next paper raises some more complex questions about the interaction between policy and literacy pedagogy in the social context of the classroom. Amelia Hempel Jorgenson and colleagues at the Open University report on a research project that used a case study design to investigate what happens when schools teaching in areas of high social disadvantage champion reading for pleasure. Using the concept of "pedagogies of poverty" (Hayes et al., 2009), they were aware that those schools under greatest pressure from a high accountability system often retreat into the least imaginative and most restrictive pedagogy, focused on drilling students into mastering basic competences. They hoped that a commitment to reading for pleasure might open up new possibilities for pupils to express a sense of agency in the classroom and thus take more control over their own learning. This might lead to higher engagement with a more interesting variety of reading materials that in the longer term would reap rewards. In practice only one of the four case study schools produced a reading culture that directly expressed volition and engagement, with the other cases much more narrowly focused on a reading for proficiency agenda that precluded encouragement to read widely. The paper poses questions about how schools can break out of the tight frame that a high stakes high accountability culture places them in and instead develop a pedagogy that enriches students' lives and life chances.

The fifth paper in this Special Issue, 'Reading for pleasure: Whose job is it to build lifelong readers in the classroom?', takes us to Singapore and a research project designed to explore whether teachers consider it part of their responsibilities to promote wider reading amongst their pupils. Singapore consistently ranks highly in international assessments of literacy proficiency but the team led by Rhoda Myra Garces-Bacsal wanted to know if this translates into wider lifelong reading, and whether teachers would see this as an important goal that they should seek to promote. Using a survey design, and taking a cohort of teachers studying for Masters level qualifications, the research found that few teachers took an active interest in reading for themselves in their own time; fewer still thought it was part of their job to support children's reading; yet almost all could identify strategies that would encourage children to read more. Against a backdrop of policy initiatives designed to persuade Singapore's citizens and residents to read more widely, the authors ask what part should educators be prepared to play? Their work raises questions about the extent to which teachers across the world perceive they have a responsibility to foster the volitional act of reading and the extent to which this is conceived of as a shared social and moral responsibility.

The final paper by Rebecca Parry and Lucy Taylor entitled 'Readers in the round: holistic approaches to children's engagement with texts' links reading for pleasure to the creation of written texts. 
Following in a line of work well-represented by Ann Haas Dyson, Jackie Marsh and John Potter, the authors consider how a range of cultural reference points from diverse media sources weave their way into oral storytelling in the primary classroom and from there find their way into children's written texts. The children's agency, expressed in their storytelling in these different modes, depends upon the materials they bring into the classroom from their wider reading and their recognition of the different ways in which these materials can then be re-organised and re-framed in a new context. Drawing on Oatley's (2003) concept of 'writingandreading' in which experience in reading is intrinsically bound to experience in writing, the authors remind us of the deep connection between reading and writing and the productive relationship between the two. They rightly argue that reading for pleasure should not be viewed in isolation, but as part of children and young people's wider literacy development.

The papers in this Special Issue demonstrate some of the key preoccupations in the field. They are reminders of the importance of continuing to explore the boundaries between the classroom and lived lives and of recognising the situated complexities of fostering children's deep engagement as readers. As texts and the possibilities of reading and writing across different digital media proliferate outside formal education, it is sometimes hard for classroom practice to know how to keep up and challenging to ensure that the pedagogic practices which are meant to support volitional reading actually do so. In England where reading for pleasure is now mandated at the primary phase, many schools are eagerly taking up the mantle - time, money and effort is being expended on creating reading environments, buying new texts, running reading competitions and parents' events and offering independent reading time for instance. Such a response is encouraging, but close documentation of the influence of such activities on young readers is also needed, one informed by research and recognition of the social, relational nature of reading. In their different ways these papers suggest some core principles to follow for research and practice.

\section{References}

Cremin, T. Mottram, M. Powell, S, Collins R and Safford K. (2014) Building Communities of Engaged Readers: Reading for pleasure London and NY: Routledge.

Bennett, J. (2001) The Enchantment of Modern Life: attachments, crossings and ethics. Princeton: Princeton University Press.

Hayes, D., Johnston, K. and King, A. (2009) Creating enabling classroom practices in high poverty contexts: The disruptive possibilities of looking in classrooms. Pedagogy, Culture \& Society. 17. 3, pp. 251-264.

Moss, G., and McDonald, J.W. (2004) The borrowers: library records as unobtrusive measures of children's reading preferences. Journal of Research in Reading. 27. 4, pp.401-412.

Oatley, K. (2003) Writingandreading in Gavins, J. A. Gerard, J. (ed.) Cognitive Poetics in Practice. London: Routledge.

OECD (2002) Reading for change: performance and engagement across countries: Results from PISA 2002, New York, Organisation for Economic co-operation and Development. 
OECD (2010) PISA 2009 Results: Learning to Learn - Student Engagement, Strategies and Practices (Volume III). Paris: OECD

Rosenblatt, L. (1995) Literature as Exploration, New York, Modern Languages Association of America. 